\title{
Do Somatic Cells Really Sacrifice Themselves? Why an Appeal to Coercion May be a Helpful Strategy in Explaining the Evolution of Multicellularity
}

\author{
Adrian Stencel $^{1}$ D . Javier Suárez ${ }^{1}$ (D)
}

Received: 11 August 2020 / Accepted: 30 January 2021 / Published online: 9 March 2021

(c) The Author(s) 2021

\begin{abstract}
An understanding of the factors behind the evolution of multicellularity is one of today's frontiers in evolutionary biology. This is because multicellular organisms are made of one subset of cells with the capacity to transmit genes to the next generation (germline cells) and another subset responsible for maintaining the functionality of the organism, but incapable of transmitting genes to the next generation (somatic cells). The question arises: why do somatic cells sacrifice their lives for the sake of germline cells? How is germ/soma separation maintained? One conventional answer refers to inclusive fitness theory, according to which somatic cells sacrifice themselves altruistically, because in so doing they enhance the transmission of their genes by virtue of their genetic relatedness to germline cells. In the present article we will argue that this explanation ignores the key role of policing mechanisms in maintaining the germ/soma divide. Based on the pervasiveness of the latter, we argue that the role of altruistic mechanisms in the evolution of multicellularity is limited and that our understanding of this evolution must be enriched through the consideration of coercion mechanisms.
\end{abstract}

Keywords Altruism $\cdot$ Evolution of multicellularity $\cdot$ Kin selection $\cdot$ Major transitions in evolution $\cdot$ Microbiome

\section{Introduction}

The evolution of multicellularity is, according to Maynard Smith and Szathmary (1995), one of the major transitions in evolution, i.e., one of those events in the history of life in which certain units lose their capacity to reproduce independently as a result of their formation of higher-level units capable of reproduction as a whole. In the case of the evolution of multicellularity, independently reproducing cells, as they evolved into multicellular individuals, lost their independent capacity for reproduction. Multicellular individuals have the capacity to reproduce themselves and to control the reproduction of the cells of which they are composed. These cells comprise two main subsets: somatic cells, whose reproductive regime is controlled and limited to the ontogeny of

Adrian Stencel and Javier Suárez declare that their contributions to the article have been equal.

Javier Suárez

javier.suarez@uj.edu.pl

1 Faculty of Philosophy, Jagiellonian University, Kraków, Poland the multicellular organism, and germline cells, which give rise to cell lineages with the capacity of creating new multicellular individuals. The study of the evolutionary origin of multicellularity raises a question concerning the type of mechanisms that made this transition feasible. In other words, the issue consists of uncovering the type of biological structures that appeared to prevent the excessive reproduction of the somatic cells within a multicellular body, and the delegation of their reproductive capacity to a specialized subset of these cells. The topic has received a great deal of attention from the point of view of experimental evolution (Ratcliff et al. 2012; Hammerschmidt et al. 2014; Herron 2016; Rosenzweig and Sherlock 2018; Herron et al. 2019), theoretical biology (Michod and Roze 2001; Fisher et al. 2013; West et al. 2015; ̊̊gren et al. 2019), and the philosophy of biology (Okasha 2006; Godfrey-Smith 2009; Veit 2019), constituting a hotly debated field of research which requires an interdisciplinary outlook.

One of the most pressing questions in the context of major transitions in evolution concerns the phenomenon of reproductive sacrifice. Why did certain formerly reproducing entities give up their reproductive potential to aid the reproductive abilities of other elements within a higher-level 
system? How do entities of this type evolve? As applied to the case of multicellular organisms, why do somatic cells sacrifice themselves in order to guarantee that germline cells can transmit their genes to the next generation, instead of doing the transmitting themselves? One conventional answer to this question refers to the theory of kin selection, or inclusive fitness (Bourke 2011; West et al. 2015). According to this explanation, since all the cells in a multicellular organism derive from a single cellular bottleneck, they are all nearly genetically identical, i.e., characterized by the highest possible degree of biological relatedness. This promotes altruistic cell-to-cell behavior, as the same genes will be found in the next generation regardless of which cell transmits them. As a consequence, according to the kin selection explanation of multicellularity, the somatic cells of a multicellular organism sacrifice their reproductive capacity to enhance the reproduction of germline cells, since both subsets of cells bear the same (or very similar) genes. This explanation entails the consideration of multicellular organisms as altruistic or cooperative consortia of cells whose cohesion derives from the existence of altruistic cell-to-cell mechanisms, which have evolved due to a high degree of genetic relatedness (Michod and Roze 2001; Queller and Strassmann 2009, 2016; Folse and Roughgarden 2010).

The aim of the present article is to contest this idea by showing that the relevance of altruistic mechanisms in the evolution of multicellularity is more limited than advocates of kin selection theory suggest. We will show that contemporary research on multicellularity suggests that a stronger emphasis should be placed on so-called policing mechanisms (Clarke 2010, 2013), which are among the most important biological mechanisms making the evolution of multicellularity possible. Policing mechanisms involve biological structures that control any biological entity that compromises the survival of the organism in question, including multicellular organisms. In the case we study in this article, policing mechanisms involve the biological structures that actively control the excessive reproduction of somatic cells in order to guarantee the long-term survival of a multicellular organism and the transmission of germline cells. We will cite the pervasiveness of policing mechanisms in multicellular organisms to argue that multicellularity should be conceived as a system of coercion whereby germline cells guarantee their transmission to the next generation. Importantly, our view does not imply the lack of any role whatsoever for altruistic mechanisms in the evolution of multicellularity. The separation of germ and somatic cells has occurred many times, and in many different lineages, within the history of life; thus, we believe there is no single and unique way in which the evolution of multicellularity occurs. Furthermore, we believe that both altruism and coercion may have played a role in the evolution of multicellularity even within the same lineage, e.g., at different stages during its evolution. Thus, our point is that a more prominent role should be attributed to policing mechanisms in theoretical, experimental, and philosophical research on multicellularity than is currently the case due to the influence of the inclusive fitness view of multicellularity evolution.

Before proceeding, we need to clarify that by the evolution of multicellularity we mean not only its origin but also its evolutionary maintenance. In other words, in our framework, policing mechanisms, as biological structures whose evolution triggers the evolution of multicellularity (questions about origin), as well as reinforcing the biological adaptiveness of multicellular forms of life (questions about maintenance), should be assigned a more prominent role. For reasons of space, and to keep our point concise, we will focus here mostly on questions of the latter type. In other words, we will focus here on research on the policing mechanisms of complex multicellular organisms that are already characterized by separate germ/soma lines. We will show that coercion plays a key role in the maintenance of multicellularity in these lineages. Furthermore, we will show that in many situations, coercion seems to describe the ongoing situation more accurately. As a result, we argue that it should not be assumed a priori, without further examination, that the evolution of somatic cells is driven by altruism.

Our article will proceed in four stages. Firstly, we will briefly summarize an interpretation of the inclusive fitness theory of the origin of multicellularity, according to which somatic cells constitute altruistic consortia of cells that have evolved due to their genetic relatedness to germline cells (the next section). Then, we will show that the lack of reproduction in somatic cells may have two causal explanations. One explanation invites us to consider this lack a form of altruism; another, a form of coercion (third section). Building on this, and relying on some recent evidence from biological studies, we argue that it is better to think of somatic cells as being coerced to sacrifice themselves rather than as being altruistic (fourth section). In this vein, we defend the idea that somatic cells do not sacrifice themselves voluntarily, but are rather coerced to do so. Multicellularity should thus be conceived as a coordinated system of coercion (fifth section).

\section{Inclusive Fitness Theory and Germ/Soma Separation}

Explaining the evolution of multicellularity requires explanation of the evolution of two subsets of cells: somatic and germline. This distinction, while particularly salient in the case of multicellular organisms, such as members of our own species, has evolved to different degrees in many species, sometimes as a consequence of complex trade-offs, as in the social amoeba Dictyostelium discoideum (Strassmann 
et al. 2000; Sathe et al. 2010; Nanjundiah and Sathe 2011). The difference between subsets concerns their reproduction: somatic cells do not pass their genetic material on to the next generation, but perform a variety of functions within an organism that are essential for the reproduction of the organism's other subset, germline cells. Somatic cells constitute the structural basis of the organism's nervous and digestive systems and are responsible for the proper functionality of organisms in many different dimensions (physiology, development, etc.). Germline cells, on the other hand, make up the subset responsible for passing genetic material on to the next generation and do not take part in any of the activities required for the proper functionality of the organism. The existence of these two types of cells seems a priori puzzling: at first glance it is not clear how somatic cells could be maintained in a population, since they do not pass their genes on to the next generation; therefore, their (direct) fitness is zero (Brunet and King 2017; Suárez and Deulofeu 2019). Fortunately, the inclusive fitness theory provides an answer to this question (Hamilton 1964; West et al. 2007; Bourke 2011).

By applying the notion of inclusive fitness to the question of how the division between somatic and germline cells might evolve, one can explain this division as an extreme version of altruistic behavior. Indeed, this type of argument, which has been explicitly endorsed by several authors (see Table 1), runs as follows: From the perspective of somatic cells, it makes sense to sacrifice themselves, because they are genetically related to germline cells, both cell lines being derived from the same zygote and thus sharing the same genetic content (with minor exceptions due to mutations). As a result, if a somatic cell does not reproduce, but enhances the reproduction of germline cells, then the genes that code for this type of non-reproducing behavior may become stabilized in the population, provided that the long-term benefit acquired by somatic cells through their indirect reproduction via germline cells outweighs the benefit realized by those cells that do not renounce reproduction in favor of forming a multicellular consortium. This idea can be expressed by applying Hamilton's rule, according to which somatic cells will evolve if and only if the evolutionary benefits derived from their relatedness to germline cells outweigh the costs resulting from their lack of individual reproduction (Hamilton 1964). In other words, even though the direct fitness of somatic cells is reduced to zero, their indirect fitness may be enhanced to the extent that their inclusive fitness is enhanced overall. Thus, the genes coding for this behavior may be passed on to the next generation and, as a result, this trait may be preserved within the population. Note that the key assumption of this explanation is that genetic relatedness between somatic and germline cells explains the division of reproductive labor characterizing multicellularity. In kin selection theory this type of sacrifice, called altruism, is considered to be one of the driving forces of evolution.

The inclusive fitness theory, based on the concepts of genetic relatedness and altruism, provides an explanation for the existence of sterile somatic cells, and consequently for the evolution of multicellularity. As Strassmann and Queller (2010, p. 605; see also Table 1) put it:

Fraternal organisms comprised of like units include multicellular organisms and those made up of mul-

Table 1 The idea that somatic cells sacrifice themselves and thereby enhance their inclusive fitness is a very popular one

\footnotetext{
"The somatic cells of a multicellular animal are clonal and sacrifice their own reproductive potential for the common good of the germ line. The theory of kin selection (Hamilton 1964) allows us to view these somatic cells as kin-selected altruists, since co-operation is advantageous to the survival of the 'group' of related cells (the multicellular individual) over the long term."

"When fruiting bodies contain only one clone, like multicellular animals, sterile stalk cells favoured by kin selection genes for facultative sterility can spread if they help copies of themselves in the reproductive cells."

"Since the cells in the multicellular organisms all have the same genotype, kin selection assures us that sacrifices made by somatic cells are selective as long as the germline cells are able to reproduce more successfully than all of the cells would have been able to acting independently."

"From this standpoint, a multicellular organism is a eusocial society of cells in which the members of the society happen to be physically stuck together; the more fundamental glue, however, is the clonal relatedness that (barring mutations) gives each somatic cell within the organism a common interest in promoting the production of gametes."

"From a kin selection perspective, an organism is a social assemblage of cells, united by common genetic interest and gene transmission by proxy (Wilson 1975). Common genetic interest follows from all members of the assemblage being direct lineal descendants of a zygote. Reproduction by proxy arises through allocating gene transmission to a privileged group of gametogenic members of the society (the germ line), with all the other members of the group (the soma) altruistically sacrificing their own reproduction to advance reproduction by these proxies. This arrangement works because the privileged gametogens are close genetic relatives of the altruistic members of the soma, so that genes transmitted by the privileged proxies are identical to those that would be transmitted if the somatic altruists reproduced themselves."

(Nunney 1999, p. 493)

(Hunter 2009, p. 142)

(Bourke 2011, p. 3315)

(Turner 2013, p. 220)
}

(Strassmann et al. 2000, p. 965) 
tiple individuals of the same species. They are held together by kinship and some units may therefore sacrifice themselves for others who will transmit the same genes.

Although the theory of inclusive fitness offers a possible interpretation of how the germ/soma separation can evolve, we think that this interpretation is more complex than this theory suggests, as many more mechanisms, not necessarily altruistic, may underlie its evolution (Okasha 2006; Nowak et al. 2010; Durand 2020). This is because the concept of biological altruism has a very specific meaning (Gardner and West 2014), and not every biological mechanism underlying the evolution of the germ/soma separation is of this type. To say that a given behavior is altruistic, it must be performed by the organism as a means of reducing its direct fitness and substantially enhancing its indirect fitness. In other words, the organism must be in control of, i.e., must be causally responsible for, these changes in its inclusive fitness. We do not think that this generally happens in the case of somatic cells; in most circumstances, these cells have evolved mechanisms to reduce their direct fitness and to enhance the fitness of germline cells only secondarily, i.e., as a product of selection. Hence, they do not play the prominent role ascribed to them by the kin selection theory. Rather, the multicellular organism has primarily evolved policing mechanisms that coerce somatic cells and cause them to sacrifice themselves. To express it in another way: somatic cells do not sacrifice themselves; they are coerced to do so. In the fourth section we will show why this is the case. But first, we will argue why an indirect increase in the genes borne by the unit does not necessarily result from altruistic behavior, even though the unit seems to be sacrificing itself.

\section{The Story of Two Sisters: Different Causes of Sacrifice}

Biological sacrifice may entail two different causal explanations, even though in both scenarios the same individual is being sacrificed and contributing to the indirect increase of its genes in the next generation derived from the sacrifice. Only one of the scenarios should be regarded as a display of altruistic behavior enhancing the inclusive fitness of those individuals that behave this way; the other constitutes a case of coercion in which the number of these individuals' genes in the next generation may be increased accidentally. Our idea was inspired by the book (and the film based thereon) My Sister's Keeper, in which a child is born to serve as a reservoir of organs for its older sister, who is very ill, in order to keep her alive. Here we will present a conceptual scenario, based on this situation, that will help to shed light on the different type of mechanisms by means of which a multicellular organism can maintain germ/soma separation.

Suppose that there are two individuals: two sisters who are identical twins and thus genetic clones. Suppose that they are very ill. Specifically, they cannot survive or reproduce unless some of their organs (kidneys, heart, etc.), which are wearing out very quickly, are replaced. However, these organs, which are characterized by a high level of histocompatibility, can easily be transplanted from one sister into the other. As it happens, in fact, they have complementary ill organs, i.e., a healthy organ in one sister is unhealthy in the other and vice versa. In this scenario, if one sister donates her organs to the other, the latter is enabled to survive and reproduce. In other words, one sister can survive and reproduce only by sacrificing the life of the other. Furthermore, in genetic terms, this seems to be very beneficial for the sister donating her organs, since, being identical twins, the sisters share the same genetic code; thus, even if one fails to reproduce, her genes will be transmitted to the next generation.

The above scenario presumes that a given gene in the body of these twins will persist in the next generation only if one twin sacrifices herself. If neither sacrifices herself, neither will transmit her genes to the next generation. Suppose that one of the sisters sacrifices herself. Should this sacrifice count as a case of biological altruism driven by enhancement of her inclusive fitness? We think that there are two potential causal explanations that depend closely on additional details that determine whether or not the sacrifice is altruistic. Let us illustrate the idea by considering two variations of the above scenario.

\section{First Variation}

Suppose that everything is the same as in the above thought experiment: twin sisters are ill and therefore, if they want to transmit their genes to the next generation, one must sacrifice herself to serve as a reservoir of organs for the other. How might this happen? For example, sister $A$ might realize that the only way for the family to survive is to ask a doctor to slice her body into pieces and store the pieces in the refrigerator. When the time comes, the organs will be transplanted into sister $B$. Thus, saying nothing to her family, $A$ goes to a hospital and asks a doctor to do this. The family is informed following this surgery. As a result, thanks to successive transplants from $A, B$ reproduces and transmits her genes to the next generation. Thus, $A$ 's sacrifice enhances her inclusive fitness, because her behavior and her act are based on an altruistic decision. Her act reduced her level of direct fitness but led to an increase in her level of inclusive fitness. She is causally responsible for the increase in her inclusive fitness. 


\section{Second Variation}

Everything is the same as in the above scenario: again, twins are ill, and one must sacrifice her life so that their genes can be transmitted to the next generation. However, here the circumstances of this sacrifice are different. Mainly, their parents, worried that both daughters will die, decide to sacrifice one in what might be called a Sophie's choice. At one point, when the sisters fall asleep, the parents kill $A$ and take her body to a doctor, who slices it into pieces and puts all of her organs in the refrigerator. When the time comes, these organs are transplanted into the surviving sister, $B$. As a result, $A$ 's genes are transmitted to the next generation, because the transplantation of her organs enhanced the direct fitness of the recipient. However, unlike the first case, this is not an altruistic decision on the part of the sacrificing individual, but a case of coercion, in which one of the twins is forced to sacrifice herself.

The above scenarios show that there are two different causal pathways by which two identical twins can succeed in transmitting their genes to the next generation. In the first scenario, $A$ realizes that sacrificing herself is the only way to pass on her genes, albeit indirectly, to the next generation, and she decides to donate her organs to $B$. Here, $A$ is an agent of self-sacrificing or altruistic behavior; $B$ is the beneficiary. In this scenario, the genes for altruism will be passed on to the next generation. In the second scenario, however, the causal relationship is much less benign. Here, $B$ is still the beneficiary of $A$ 's sacrifice; however, it cannot be argued that $A$ is an altruistic agent characterized by

a)

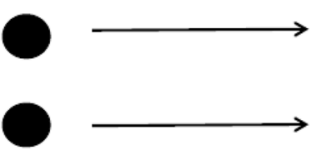

b)

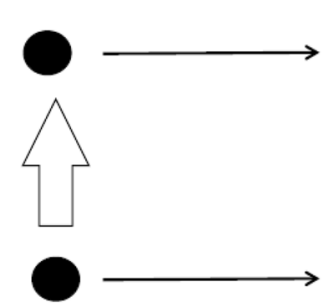

Fig. 1 The figure shows two causal pathways to alter the fitness of an individual by means of sacrifice. We assume that, due to certain limitations, only one of the two genetically identical individuals can survive, assuming the other does not reproduce. In a, neither gives up reproduction; as a result, neither reproduces. In $\mathbf{b}$, one of the individuals is in control of its direct fitness, and gives up reproduction to enhance its inclusive fitness by helping relatives (as represented self-sacrificing behavior. Of course, she is, in a way, causally responsible for her indirect transmission of genes to the next generation through $B$ 's reproduction, since $A$ 's organs are used to keep $B$ alive. Nevertheless, $A$ 's sacrifice is the result of the behavior of her parents, who force her to be killed, rather than an altruistic act. No genes for altruism appear to be involved in this scenario, and thus no genes for altruism will be transmitted to the next generation. The genes that will be passed on are genes for coercion.

Even though our scenarios are purely imaginary, they clearly illustrate the point we wish to make in this section, and which others have also expressed in different ways (Okasha 2006; Ratnieks and Wenseleers 2008; Ratnieks and Helanterä 2009; Nowak et al. 2010; Durand 2020). The enhancement of an individual's fitness may thus be driven by one of at least two different causal factors (Fig. 1). In other words, there may be more than one evolutionary strategy enhancing the fitness of a type, and thus two different types may evolve in the population. One strategy, corresponding to the first scenario, might be caused by a gene that behaves in accordance with the following situation: if you are the first to realize that not all of your siblings can survive, then you sacrifice your life in order to increase the chances of your genes being found in the next generation. The other strategy, corresponding to the second scenario, might be caused by the following behavior: if you are the first to realize that not all of your siblings can survive, then you try to kill or sterilize some of them in order to enhance the probability of propagating your own genes. In both cases, the genes shared by both

c)

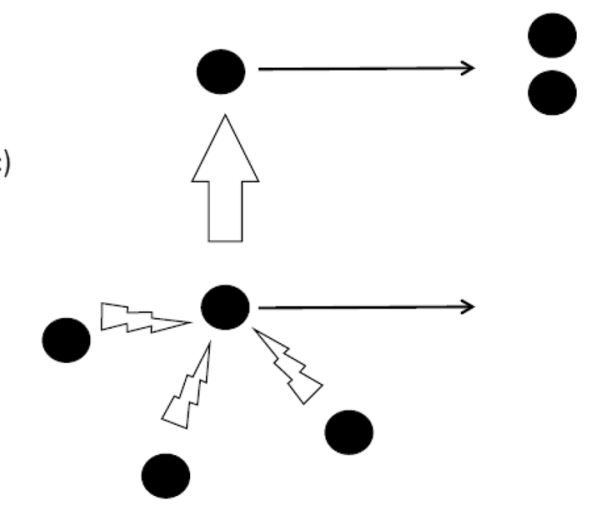

by a white arrow). This is a genuine case of altruism. In c, one of the individuals is coerced to not reproduce and thus increases the fitness of the other (as represented by a white arrow). However, in this scenario, the individual that fails to reproduce is coerced to do so by other individuals (represented by twisted arrows), and thus it does not increase its indirect fitness. This scenario represents a genuine case of coercion 
twins will reappear in the next generation. However, in the first scenario the individual sacrifices itself, and thus genes for altruism spread in the population; in the second, however, the individual is forced by others to sacrifice itself, and thus genes for coercion spread in the population.

Thus, there are two different causal pathways for the spread of genes derived from a sacrifice: altruistic, which occurs when the agent is in control of its inclusive fitness and can reduce its direct fitness in order to increase its indirect and, thus, inclusive fitness; and coercive, which occurs when a unit is forced by other units to sacrifice itself, so that they may benefit from enhancement of their inclusive fitness. If either of these pathways involve genetically similar units, they may yield the same genetic result-namely, that the genes of the sacrificed individual will be found in the next generation. However, only the first scenario would be a case of altruism, driven by the enhancement of inclusive fitness due to the fact that the unit that sacrifices itself is in control of its behavior. Here, the fact that its genes are found in the next generation is essential-without supporting relatives, this behavior could have not evolved. Contrastingly, in the second scenario, the unit is not in control of its inclusive fitness, and the fact that the genes of the sacrificed individual are found in the next generation is accidental-one can easily imagine a scenario in which this accident fails to occur, e.g., when coercion is triggered by individuals of different species. Given these two scenarios, we argue that the assumption that a contemporary altruistic action is the origin of a particular evolutionary behavior may be mistaken, as the behavior in question may be a product of selection triggered only after coercion had occurred, rather than its cause. In many evolutionary scenarios, altruistic and coercive behaviors tend to coexist, and understanding how they interact is the key to a proper understanding of evolution. Conversely, downgrading the role of coercion in favor of a purely altruistic view of evolution based on relatedness can obfuscate evolutionary research, as previously emphasized by several researchers (Okasha 2006; Ratnieks and Wenseleers 2008; Ratnieks and Helanterä 2009; Nowak et al. 2010; Durand 2020).

The existence of these two possibilities raises a question: which of the previous scenarios occurs in somatic cells? Do these units engage in altruistic behavior in order to enhance their inclusive fitness? Or are they rather coerced to do so in order to promote the presence of germline cells? The latter scenario would give the illusion that they are acting altruistically, as their sacrifice would cause an increase in the number of genetically similar cells-and thus some may mistakenly interpret it as a case of altruism. In the next section we will try to answer this question by arguing that the type of sacrifice that occurs in somatic cells seems more akin to a case of coercion than to a case of altruism.

\section{Somatic Cells do not Sacrifice Themselves, But are Coerced to do so: The Pervasiveness of Policing Mechanisms in Multicellular Organisms and Their Evolutionary Implications}

To understand whether somatic cells voluntarily sacrifice themselves or are coerced to do so, we need to look at the way in which currently existing multicellular organisms develop. The separation of germ and somatic cells has occurred many times and in many different ways in the history of life; thus, unfortunately, there is no single unique way in which division into somatic and germline cells occurs. Indeed, the evolutionary details vary between different species (Kosaka et al. 2007; Ohinata et al. 2009; Swartz and Wessel 2015). However, it appears that these separations can be divided, following Swartz and Wessel (2015), into two main mechanisms: inductive and preloaded mechanisms of specification.

Specification via inductive interactions refers to the signaling by cells to a cell in an embryo whose destiny (i.e., whether it will become a somatic or germline cell) depends on its location within the embryo and on the way it experiences certain developmental cues. Indeed, cells must be in the right place at the right time during development to pick up certain signals from other cells that allow them to mature into germline cells. This process varies among species, although the pattern remains the same. For example, in mice, the opportunity to become germline cells is limited to a very small set of cells: specifically, cells from the proximal portion of the epiblast (Ohinata et al. 2009; Swartz and Wessel 2015). These cells are transformed into germline cells after receiving certain signals from extra-embryonic tissues adjacent to the embryo, which initiate a transcriptional program leading to the development of germline cells.

Specification via preloading refers to the (maternal) inheritance of certain determinants responsible for deciding that certain cells will become germline cells. These determinants, made of proteins and mRNA, are collectively known as germ plasm. They are often enriched in a certain region of the egg and, as zygotes continue to divide following fertilization via cleavage, certain descendants (called blastomeres) acquire these determinants, which basically direct them to become germline cells. This kind of germline determination can be found in many species. In one, the zebrafish, germ plasm, called a Balbiani body, which, during oogenesis, is vegetally localized and contains nanos and vasa RNAs as well as DAZL RNA (Kosaka et al. 2007; Swartz and Wessel 2015), is displayed. Following fertilization, this germ plasm material is transferred to the animal pole of the zygote and is 
enriched at the distal ends of cleavage furrows. It is then inherited by four blastomeres; this determines their fate as germline cells.

These two examples reveal an interesting fact about germ/ soma separation. That some cells become somatic and others germline cells is not the result of the internal biological mechanisms of any cell in control of its inclusive fitness such that it gives up its own reproduction and supports that of its genetically identical relatives. Rather, this division is driven by certain system-level mechanisms that push some cells in a somatic direction, whereas others are pushed towards the germline role. In other words, cells become somatic (or germline) cells because they are born several generations after fertilization in a specific location within the developing embryo or in the adult organism. The cells themselves, however, play a very small role in the process of becoming somatic or germline cells, as this depends on activating patterns in their organismic environment. In a sense, it can be argued that their place within the organism was decided by the system long before their birth.

Furthermore, the place of not only a given cell, but its entire lineage (i.e., several hundred thousand generations), is decided before its birth. In other words, the fact that a given cell is born several generations after fertilization and in a specific location within the growing body also condemns thousands of its descendants to become somatic cells. They are condemned to play this role because it was assigned to their ancestors, since, when a cell becomes a somatic cell, so does its entire lineage. This is extremely problematic if one retains the idea that somatic cells sacrifice themselves for the good of the whole. In the type of process we are illustrating, the cells are not causally responsible for the biological process or processes that transform them into somatic cells, i.e., they are not in control of their inclusive fitness. If the process of the development of organisms is analyzed from this perspective, it makes no sense to assume that somatic cells altruistically sacrifice themselves for the sake of germline cells, as the process or processes of development seem not to be grounded in any altruistic mechanism. Let us elaborate the three reasons why we think this is true.

Firstly, somatic cells, as a subtype, simply do what all cells do: reproduce. It can be argued that, although our point is true of later stages of development, during its early stages, when the division between germ and soma first arises, somatic cells sacrifice themselves as a consequence of inter-cell communication. However, we believe that, in terms of defending the altruistic character of somatic cells, this is an incorrect argument, as it misrepresents what these cells do within an organismal context. Somatic cells come into existence as units that are supposed to perform certain functions within the organism. There is little room for choice, since the system has transformed them into certain types of cell (muscle, nerve) that cannot live outside the host environment. Within this context, somatic cells can do only what cells do, namely, reproduce. In accordance with this observation, Buss (1987) has consistently argued that somatic cells are characterized by a level of fitness higher than that of germline cells during the ontogeny of the multicellular organism (see also Okasha 2006). During this specific time frame, somatic cells reproduce and give rise to lineages that form the tissues and organs of the multicellular organism and thus temporarily outcompete germline cells. This is true even though they are destined to be outcompeted by germline cells in the long term, i.e., on the evolutionary time scale of the multicellular organism. What we wish to emphasize is that this simple observation is at odds with the idea that somatic cells sacrifice themselves.

Secondly, it seems unreasonable to assume that the action of altruistic mechanisms, even if feasible at some point during development, can also be attributed to the whole to which a somatic cell gives rise. As we have noted, when a cell becomes a somatic cell, so does its entire lineage. Our point here is that even though a particular cell in an early stage of development of an embryo may sacrifice itself and become a somatic cell, hence indirectly enhancing its inclusive fitness, it does not follow that all of the cells in the lineage to which this cell gives rise will also decide to sacrifice themselves. For example, the environment may change, in which case it may be more advisable for any of these cells to leave the group and start living on their own, because in this new environment they can better enhance their inclusive fitness through enhancing their direct rather than indirect fitness. However, in the case of somatic cells, as mentioned above, this is impossible, because these cells have been so completely transformed by the system that they can no longer leave it.

Thirdly, somatic cells tend to rebel against the system into which they are born, giving rise to processes of uncontrolled cell growth, including processes such as cancer. In fact, the formation of cancer cells is nowadays believed to be very common, occurring almost constantly (Afshar-Sterle et al. 2014). Cancer is commonly considered to be a disruption of the cooperative system, a form of cheating (Nunney 1999; Strassmann and Queller 2010). But can we really agree to this, given what has been said in the previous paragraphs? A cell in the body of a multicellular organism is constantly being coerced to sacrifice itself. Is it really justified to say that a cell that is trying to escape the place the system has prepared for it within the organism is cheating? A more plausible interpretation is that the multicellular system is the cheater, since it generated the mechanisms that enable some cells to be employed as somatic cells, thus hampering what would otherwise be their normal reproductive behavior. In our approach, cancer must be interpreted instead as an anti-coercive adaptation. In most cases, cancer will lead to the destruction of the system, for most cancers are not 
transmissible to other individuals in the population. However, sometimes cancer cells can avoid their fate and go back to the free-living state of their ancestors. Tasmanian devils provide a canonical example of the latter phenomenon, in which some cancers have evolved into parasites that can move horizontally between hosts (Pearse and Swift 2006).

\section{Multicellularity as a Coordinated System of Coercion}

The previous discussion raises the following question: if somatic cells do not sacrifice themselves, and thus their evolution cannot be explained as the result of altruistic genes, how can we explain the existence of multicellular organisms that have reached an irreversible state (i.e., containing somatic cells that cannot survive outside the multicellular organism)? In the context of the previous discussion, we are inclined to say that somatic cells are sacrificed, and thus the genes that have been selected for are genes for coercion. Let us explain this point more clearly, as it constitutes the core of our view of the evolution of multicellularity.

In our view, the system extrinsically coerces somatic cells in a developing multicellular organism that grows from a fertilized egg (or even from earlier stages, as in the case of determination by means of preloading initiated prior to fertilization). This system is composed of a set of interacting cells that communicate and implement certain patterns of behavior, among which the most basic are so-called policing mechanisms (Buss 1987; Okasha 2006; Clarke 2013). By policing mechanisms, we mean any mechanisms that, through coercion, shape the behavior of the various constituent parts of the multicellular organism (Michod 2000). Coercion can be carried out in many ways; it includes phenomena such as nutrient deprivation, direct alteration of the physiological cycle of a cell, direct induction of cell death, or direct reduction of a cell's reproductive rate. For example, the immunological system has been widely recognized as one of the first and most universal policing mechanisms (Pradeu 2010, 2011, 2019; Chiu and Eberl 2016; Tauber 2016).

Note that policing mechanisms, which can be seen as a proxy for identifying the existence of a unit of selection at a level of the biological hierarchy (Suárez 2019, pp. 161-162), do not exist, in our account, as a by-product of co-operation, as some interpretations of inclusive fitness theory suggest. On the contrary, we argue that policing mechanisms are the core of the basic coercive system that gives multicellular organisms the appearance of biological individuals characterized by "low conflict and high cooperation" (Queller and Strassmann 2009, 2016; Folse and Roughgarden 2010). In other words, multicellular organisms are coordinated systems of coercion in which the policing mechanisms act as guards, guaranteeing the sacrifice and cooperation of somatic cells. In this vein, policing mechanisms identify all non-cooperative cells (along with any lineages they may have produced) and eliminate them from the system.

One intriguing question in our view of multicellularity as a coordinated system of coercion concerns the role of programmed cell death, which is present in species as diverse as yeast (Wloch-Salamon and Bem 2013), green algae (Durand et al. 2011), and humans (Letai 2008), especially when the phenomenon is perceived as an adaptation (Durand and Ramsey 2019; Durand 2020). The problem arises from the observation that programmed cell death may evolve as an altruistic mechanism, in which certain genes have been selected to favor other related cells when the system faces extreme biotic or abiotic conditions. In our interpretation, it is important to distinguish clearly between cases in which this process is triggered by other cells producing signals to induce the death of the original cell and cases where the genetic program itself is intrinsic to the dying cells and is activated only in response to certain environmental conditions. In the first cases, the trait is clearly a result of coercion, in which system-level mechanisms push certain cells towards their death. We speculate that this is more likely to happen in highly evolved multicellular organisms, whose cells are highly integrated in a complex array of pathways. For instance, in humans, there are mechanisms that enable the elimination of dysfunctional cells (Letai 2008); a hallmark of cancer is its ability to avoid being detected by these mechanisms (Hanahan and Weinberg 2011). This reinforces our claims that cancer is an anti-coercion adaptation by some cells and that somatic cells are not in control of their sacrifice, i.e., their evolution is not primarily a result of altruism or kin selection; rather, they are constrained by system-level mechanisms not to become cancerous; otherwise the organism will induce their death.

In the second case, on the contrary, the behavior would more likely represent a case of altruism, whenever it is feasible to find the specific genes that code for that behavior and the death in question is not a result of nonadaptive processes. We think that this type of programmed cell death is more likely to occur in less developed forms or even in some loose aggregations of unicellular organisms. In these situations, the groups in question are not integrated to the same degree, and the individuals composing these aggregates have more control over their potential act of sacrifice. Therefore, in the case of external environmental perturbations (e.g., increased heat), some individuals may initiate programmed cell death in order to ensure the success of their relatives and so to enhance their inclusive fitness (Durand et al. 2011).

These two scenarios should be taken not as an explanation of how the evolution of programmed cell death must always occur, but rather as a suggestion as to the most likely series of events. Yet, since the process is a very 
complex phenomenon, it may well have evolved differently in different lineages; finding a common general pattern is thus nearly impossible (Durand and Ramsey 2019; Durand 2020). Note that our view of the evolution of programmed cell death mirrors our view of the evolution of multicellularity: as a variable process whose origin differs between distinct lineages, showing a mixed pattern fluctuating between altruistic and coercive mechanisms (section four). Yet our key message is the same: when the research question concerns the maintenance of the trait, policing or coercive mechanisms should be assigned a role either equivalent to or greater than that of altruism.

To sum up, let us return to the dichotomy introduced in the last section. Which of the two scenarios mentioned in the third section better explains the existence of somatic cells? Based on what we have shown in the last two sections, we think that the second scenario describes the situation of somatic cells much more accurately: somatic cells are placed in the role of units which are not in control of their inclusive fitness, coerced to sacrifice themselves; in other words, despite the genetic relatedness between somatic and germline cells, the mechanisms holding them together to form a multicellular organism are based not on altruism, but on strict policing. In the example we provided in section three, coercion was possible because the sisters trusted their parents, who were able to impose the sacrifice of one sister, killing her in her sleep, so that at least one sister would survive. In the case of multicellular organisms, the mechanisms that make coercion possible appear during development, including the developmental stages before and after birth; during this process, the offspring cells inherit certain developmental cues that push them towards a certain place within the organism. As the organism continues to develop, these cells continue to push other cells in certain directions. This, apparently, is easy, because new cells are constantly emerging from other cells, and certain developmental cues and signals surround these emerging cells beginning in their early existence, when they may be just as vulnerable and defenseless as the sleeping sister in our second scenario.

This raises the following question: if multicellular organisms are systems of coercion, why is germ/soma separation, along with the most complex cell specialization, always accompanied by a high level of genetic relatedness between cells (for comparative analysis, see Fisher et al. 2013)? The first aspect to be pointed out here is that the cells of a complex multicellular organism are not really genetically identical. For instance, genetic diversity is generated during development in different tissues, resulting in somatic mosaicism (Frank 2014). Genetic mosaicism shows that genetic identity among cells is not necessary for maintaining the evolution of multicellular lineages. In addition, some research shows that it may not even be very important during the early stages of evolution; other factors, such as cell size and motility, may be more relevant (Sathe and Durand 2016).

Even if our arguments concerning mosaicism are accepted, it may still be argued that the structures of multicellular individuals, even if not genetically identical, derive systematically from a single cell. In other words, if, as we argue, multicellularity is grounded on coercion, why do zygotes prefer to exploit their descendants by keeping them around instead of turning all of their descendants into germline cells and making their somatic tissues out of other bacterial cells that are swimming around? Part of the explanation may be that, inasmuch as the zygote produces the remainder of the cells, coercion is easier to exert than it is in other type of cells, as the pathways for coercion can be induced from the beginning. Moreover, this picture of multicellular organisms as monozygotic individuals is not quite so simple. The existence of chimeras in different taxa, especially in plants, is a standard example (Clarke 2011; Frank and Chitwood 2016). Additionally, recent research has suggested that most multicellular organisms live in close association with an abundant number of microbes which constitute their microbiome and which collectively perform a large number of vital functions. Doubtless, this calls our understanding of organisms as monogenetic organisms into question; one potential interpretation of the evidence would recast the concept of individuality to show that genetic relatedness is not as fundamental as was previously thought (Dupré and O'Malley 2009; Gilbert et al. 2012; Roughgarden et al. 2018; Stencel and Proszewska 2018; Suárez 2018).

Alternatively, one may respond to the question by accepting the evidence and arguing that the division into somatic or germline cells, with a high degree of specialization and integration, is more easily achieved with genetically similar cells, since altruistic mechanisms can thus eventually evolve and reinforce the effects of the coercive mechanisms. This response would, of course, be compatible with the acknowledgment that such a structure is not hermetic, and that microbes can thus be eventually incorporated. In this interpretation, evidence about the role of the microbiome would be interpreted in terms of a form of enrichment of the original structure with additional, even genetically distinct, individuals capable of carrying out some of the functions of somatic cells or even of providing a new biological feature of some kind. This interpretation is compatible with recent evidence that suggests that these microbial components would enable the development of a more robust immune system, as well as the evolution of some complex features in their hosts, e.g., the ability to digest certain nutrients, as in the case of ruminants which rely on microbes enabling them to digest the most complex plant polysaccharides (Henderson et al. 2015; Gilbert 2020; Triviño and Suárez 2020). However, whether microbes finding themselves inside the body of multicellular organisms should be considered the results 
of coercion by the host or of some other cause needs to be discussed separately, as it exceeds the scope of this article (for our view on this phenomenon, see Suárez and Stencel 2020).

Overall, we contend, contemporary biological evidence suggests that genetic relatedness is not a necessary requirement for the maintenance of multicellularity (especially given the abundance of mosaicism, chimaeras, and symbiotic associations). Nor should it be taken as a default hypothesis in explaining why multicellular forms of life have evolved. This does not mean that genetic relatedness plays no role at all. In fact, in our framework, forms of altruism that derive from genetic relatedness may be especially important in the early stages of evolution (questions of origin), or may reinforce processes of coercion. However, in many cases, genetic relatedness may simply be a product of evolution, rather than its cause, especially in a context in which coercion may be a more evolvable property (for further criticism concerning the role of relatedness, see Okasha 2006; Durand 2020).

\section{Concluding Remarks}

In this article we have shown two important things. First, the fact that one individual is sacrificed for the benefit of a genetic clone does not mean per se that this is a case of altruism driven by inclusive fitness, nor is this necessarily true ("The Story of Two Sisters: Different Causes of Sacrifice"). This demonstrates that, even though thinking of organisms as agents with certain intentions (they "sacrifice themselves," "cheat," etc.) is a powerful tool (see Okasha (2018) for a review and philosophical justification), it may sometimes be misleading, and thus mask the true evolutionary story behind what has been going on (Godfrey-Smith 2009, p. 5; Lloyd 2017). Thus, before accepting an altruistic interpretation based on the genetic relatedness between individuals, one must explore whether, given the biological reality, a better alternative or complement to the altruistic interpretation can be found.

Secondly, we have argued that, contrary to the popular belief that somatic cells simply sacrifice themselves in order to enhance their inclusive fitness, the situation is more complex, as in most cases they are coerced to do so by system-level mechanisms ("Somatic Cells do not Sacrifice Themselves, But are Coerced to do so: The Pervasiveness of Policing Mechanisms in Multicellular Organisms and their Evolutionary Implications"). These include genetically coded (apoptosis) as well as other, e.g., immunological, policing mechanisms ("Multicellularity as a Coordinated System of Coercion").

Our account is congruent with recent ideas suggesting that coercion must have played an important role in the evolution of complex units, e.g., social insects (Ratnieks and
Wenseleers 2008; Ratnieks and Helanterä 2009; Nowak et al. 2010; Canciani et al. 2019). Unfortunately, our analysis was limited to currently living complex organisms possessing advanced mechanisms of germ/soma separation, for which we have shown that, for most lineages, policing mechanisms play a primary role. Yet the question concerning the origin of higher levels of individuality remains open. Was the situation the same at the beginning of the evolution of germ/soma separation? In other words, when germ/soma separation starts, are policing mechanisms behind the origin of the distinction, or are altruistic mechanisms responsible for their origin? Perhaps at the beginning somatic cells were in control of their inclusive fitness and directly sacrificed themselves, but then, as evolution continued, this changed, and now they are coerced to do so. Or perhaps coercion was present from the very beginning, and altruism evolved only afterwards, as a product of selection at that level. The latter perspective is suggested by certain evidence, such as the idea that cheaters may play a role in the origin of germ/soma separation (Hammerschmidt et al. 2014; Veit 2019). Both coercion and cheating are forms of exploitation. Whether there is a direct road from cheating to coercion is not yet clear; this question should be addressed in the future. In any case, it suggests that policing mechanisms, rather than altruistic mechanisms, must be assigned the primary role in studying the evolution of higher levels in the biological hierarchy.

Overall, our approach is not intended to eradicate altruism from evolutionary considerations. Rather, we wish to show that the observation of some costly behaviors that diminish the reproductive capabilities of their bearers, while simultaneously leading to an increase in the number of these very genes in the population, does not necessarily mean that this behavior is caused by altruism driven by kin selection. For this behavior to be caused by altruism, the actor must have been in control of it (Gardner and West 2014). Our article shows that, in many situations, somatic cells are not in control; on the contrary, they are coerced to behave in this costly way, and thus even if an increase in their number of genes in the population follows, this is only accidental. Therefore, we think that reference to coercion is very likely, in many cases, a better description of what is going on in multicellular organisms, and thus policing mechanisms should be assigned the primary role in evolutionary research. That said, many of the examples that we have used to build our argument derived from highly complex organisms (mice, zebrafish, humans), whereas it is very likely that at an early stage of evolution, or in different lineages (plants, insects, cephalopods, etc.), either altruism alone or a combination of coercion and altruism may have played a prominent role in the evolution of multicellularity. To understand the origin and maintenance of germ/soma separation, reference to both altruism and coercion, as well as to many other potentially 
important mechanisms, is justified. All of them may be relevant to different extents in different lineages and at different stages of the evolution of multicellularity.

Acknowledgments The idea of writing this paper came about when the authors spent two productive weeks together in July 2019, in the Summer School on "Microbiota, Symbiosis and Individuality," organized by the ERC IDEM team in Biarritz, and in the 2019 meeting of the International Society for the History, Philosophy and Social Studies of Biology in Oslo. We especially thank Sophie Veigl and Eörs Szathmáry for an inspiring dinner where we discussed these and other issues. Additionally, we thank Mark Canciani, Andy Gardner, and two anonymous reviewers of Biological Theory for their comments on earlier drafts. Javier Suárez wants to thank all the members of ImmunoConcept, University of Bordeaux, for the excellent discussions he had on the ideas of this paper during his research stay there in February/ March 2020. The research was funded by NCN grant Opus (Grant No. 2017/27/B/HS1/00290) to Adrian Stencel, and by NCN grant Opus (Grant No: 2019/35/B/HS1/01998) to Javier Suárez. Adrian Stencel's work is also supported by the Foundation for Polish Science (FNP).

Open Access This article is licensed under a Creative Commons Attribution 4.0 International License, which permits use, sharing, adaptation, distribution and reproduction in any medium or format, as long as you give appropriate credit to the original author(s) and the source, provide a link to the Creative Commons licence, and indicate if changes were made. The images or other third party material in this article are included in the article's Creative Commons licence, unless indicated otherwise in a credit line to the material. If material is not included in the article's Creative Commons licence and your intended use is not permitted by statutory regulation or exceeds the permitted use, you will need to obtain permission directly from the copyright holder. To view a copy of this licence, visit http://creativecommons.org/licenses/by/4.0/.

\section{References}

Afshar-Sterle S, Zotos D, Bernard NJ, Scherger AK, Rödling L, Alsop AE et al (2014) Fas ligand-mediated immune surveillance by $T$ cells is essential for the control of spontaneous B cell lymphomas. Nat Med 20(3):283-290

Ågren JA, Davies NG, Foster KR (2019) Enforcement is central to the evolution of cooperation. Nat Ecol Evol 3(7):1018-1029. https:// doi.org/10.1038/s41559-019-0907-1

Bourke AFG (2011) The validity and value of inclusive fitness theory. Proc Biol Sci 278(1723):3313-3320. https://doi.org/10.1098/ rspb.2011.1465

Brunet T, King N (2017) The origin of animal multicellularity and cell differentiation. Dev Cell 43(2):124-140

Buss LW (1987) The evolution of individuality. Princeton University Press, Princeton

Canciani M, Arnellos A, Moreno A (2019) Revising the superorganism: an organizational approach to complex eusociality. Front Psychol 10:2653. https://doi.org/10.3389/fpsyg.2019.02653

Chiu L, Eberl G (2016) Microorganisms as scaffolds of host individuality: an eco-immunity account of the holobiont. Biol Philos 31(6):819-837. https://doi.org/10.1007/s10539-016-9552-0

Clarke E (2010) The problem of biological individuality. Biol Theory 5(4):312-325. https://doi.org/10.1162/BIOT_a_00068

Clarke E (2011) Plant individuality and multilevel selection theory. In: Calcott B, Sterelny K (eds) The major transitions in evolution revisited. MIT Press, Cambridge. https://doi.org/10.7551/mitpr ess/9780262015240.003.0012

Clarke E (2013) The multiple realizability of biological individuals. J Philos 110(8):413-435

Dupré J, O’Malley MA (2009) Varieties of living things: life at the intersection of lineage and metabolism. Philos Theory Pract Biol. https://doi.org/10.3998/ptb.6959004.0001.003

Durand PM (2020) The evolutionary origins of life and death. University of Chicago Press, Chicago

Durand PM, Ramsey G (2019) The nature of programmed cell death. Biol Theory 14(1):30-41. https://doi.org/10.1007/s1375 2-018-0311-0

Durand PM, Rashidi A, Michod RE (2011) How an organism dies affects the fitness of its neighbors. Am Nat 177(2):224-232. https ://doi.org/10.1086/657686

Fisher RM, Cornwallis CK, West SA (2013) Group formation, relatedness, and the evolution of multicellularity. Curr Biol 23(12):1120-1125. https://doi.org/10.1016/j.cub.2013.05.004

Folse HJ, Roughgarden J (2010) What is an individual organism? A multilevel selection perspective. Q Rev Biol 85(4):447-472. https://doi.org/10.1086/656905

Frank SA (2014) Somatic mosaicism and disease. Curr Biol 24(12):R577-R581. https://doi.org/10.1016/j.cub.2014.05.021

Frank MH, Chitwood DH (2016) Plant chimeras: the good, the bad, and the 'Bizzaria.' Plant Dev 419(1):41-53. https://doi. org/10.1016/j.ydbio.2016.07.003

Gardner A, West SA (2014) Inclusive fitness: 50 years on. Philos Trans R Soc B 369(1642):20130356. https://doi.org/10.1098/ rstb.2013.0356

Gilbert SF (2020) Developmental symbiosis facilitates the multiple origins of herbivory. Evol Dev 22(1-2):154-164. https://doi. org/10.1111/ede.12291

Gilbert SF, Sapp J, Tauber AI (2012) A symbiotic view of life: we have never been individuals. Q Rev Biol 87(4):325-341. https ://doi.org/10.1086/668166

Godfrey-Smith P (2009) Darwinian populations and natural selection. Oxford University Press, Oxford

Hamilton WD (1964) The genetic theory of social behavior. I and II. J Theor Biol 7:1-52

Hammerschmidt K, Rose CJ, Kerr B, Rainey PB (2014) Life cycles, fitness decoupling and the evolution of multicellularity. Nature 515(7525):75-79. https://doi.org/10.1038/nature13884

Hanahan D, Weinberg RA (2011) Hallmarks of cancer: the next generation. Cell 144(5):646-674. https://doi.org/10.1016/j. cell.2011.02.013

Henderson G, Cox F, Ganesh S, Jonker A, Young W, Collaborators GRC, Jannsen PH (2015) Rumen microbial community composition varies with diet and host, but a core microbiome is found across a wide geographical range. Sci Rep 5(1):14567. https:// doi.org/10.1038/srep14567

Herron MD (2016) Origins of multicellular complexity: volvox and the volvocine algae. Mol Ecol 25(6):1213-1223. https://doi. org/10.1111/mec.13551

Herron MD, Borin JM, Boswell JC, Walker J, Chen I-CK, Knox CA et al (2019) De novo origins of multicellularity in response to predation. Sci Rep 9(1):2328. https://doi.org/10.1038/s4159 8-019-39558-8

Hunter LE (2009) The processes of life: an introduction to molecular biology. MIT Press, Cambridge

Kosaka K, Kawakami K, Sakamoto H, Inoue K (2007) Spatiotemporal localization of germ plasm RNAs during zebrafish oogenesis. Mech Dev 124(4):279-289

Letai AG (2008) Diagnosing and exploiting cancer's addiction to blocks in apoptosis. Nat Rev Cancer 8(2):121-132. https://doi. org/10.1038/nrc2297 
Lloyd E (2017) Units and levels of selection. In: Zalta EN (ed) Stanford encyclopedia of philosophy. https://plato.stanford.edu/entri es/selection-units/

Maynard Smith J, Szathmary E (1995) The major transitions in evolution. Oxford University Press, Oxford

Michod RE (2000) Darwinian dynamics: evolutionary transitions in fitness and individuality. Princeton University Press, Princeton

Michod RE, Roze D (2001) Cooperation and conflict in the evolution of multicellularity. Heredity 86(1):1-7. https://doi.org/10.104 6/j.1365-2540.2001.00808.x

Nanjundiah V, Sathe S (2011) Social selection and the evolution of cooperative groups: the example of the cellular slime moulds. Integr Biol 3(4):329-342

Nowak MA, Tarnita CE, Wilson EO (2010) The evolution of eusociality. Nature 466(7310):1057-1062

Nunney L (1999) Lineage selection and the evolution of multistage carcinogenesis. Proc Biol Sci 266(1418):493-498

Ohinata Y, Ohta H, Shigeta M, Yamanaka K, Wakayama T, Saitou M (2009) A signaling principle for the specification of the germ cell lineage in mice. Cell 137(3):571-584

Okasha S (2006) Evolution and the levels of selection. Oxford University Press, Oxford

Okasha S (2018) Agents and goals in evolution. Oxford University Press, Oxford. https://doi.org/10.1093/oso/9780198815 082.001 .0001

Pearse A-M, Swift K (2006) Transmission of devil facial-tumour disease. Nature 439(7076):549-549

Pradeu T (2010) What is an organism? An immunological answer. Hist Philos Life Sci 32:247-267

Pradeu T (2011) The limits of the self: immunology and biological identity. Oxford University Press, Oxford

Pradeu T (2019) Philosophy of biology: immunology and individuality. Elife 8:e47384

Queller DC, Strassmann JE (2009) Beyond society: the evolution of organismality. Philos Trans R Soc B 364(1533):3143-3155. https ://doi.org/10.1098/rstb.2009.0095

Queller DC, Strassmann JE (2016) Problems of multi-species organisms: endosymbionts to holobionts. Biol Philos 31(6):855-873. https://doi.org/10.1007/s10539-016-9547-x

Ratcliff WC, Denison RF, Borrello M, Travisano M (2012) Experimental evolution of multicellularity. Proc Natl Acad Sci USA 109(5):1595-1600

Ratnieks FL, Wenseleers T (2008) Altruism in insect societies and beyond: voluntary or enforced? Trends Ecol Evol 23(1):45-52

Ratnieks FL, Helanterä H (2009) The evolution of extreme altruism and inequality in insect societies. Philos Trans R Soc B 364(1533):3169-3179

Rosenzweig F, Sherlock G (eds) (2018) Essential experimental evolution. Productivity Press

Roughgarden J, Gilbert SF, Rosenberg E, Zilber-Rosenberg I, Lloyd EA (2018) Holobionts as units of selection and a model of their population dynamics and evolution. Biol Theory 13(1):44-65. https://doi.org/10.1007/s13752-017-0287-1

Sathe S, Durand PM (2016) Cellular aggregation in Chlamydomonas (Chlorophyceae) is chimaeric and depends on traits like cell size and motility. Eur J Phycol 51(2):129-138. https://doi. org/10.1080/09670262.2015.1107759

Sathe S, Kaushik S, Lalremruata A, Aggarwal RK, Cavender JC, Nanjundiah V (2010) Genetic heterogeneity in wild isolates of cellular slime mold social groups. Microb Ecol 60(1):137-148
Stencel A, Proszewska AM (2018) How research on microbiomes is changing biology: a discussion on the concept of the organism. Found Sci 23(4):603-620. https://doi.org/10.1007/s1069 9-017-9543-x

Strassmann JE, Queller DC (2010) The social organism: congresses, parties, and committees. Evolution 64(3):605-616. https://doi.org /10.1111/j.1558-5646.2009.00929.x

Strassmann JE, Zhu Y, Queller DC (2000) Altruism and social cheating in the social amoeba Dictyostelium discoideum. Nature 408(6815):965-967. https://doi.org/10.1038/35050087

Suárez J (2018) The importance of symbiosis in philosophy of biology: an analysis of the current debate on biological individuality and its historical roots. Symbiosis 76(2):77-96. https://doi.org/10.1007/ s13199-018-0556-1

Suárez J (2019) The hologenome concept of evolution: a philosophical and biological study. PhD Dissertation. University of Exeter

Suárez J, Deulofeu R (2019) Equilibrium explanation as structural non-mechanistic explanations: the case of long-term bacterial persistence in human hosts. Teorema: Revista internacional de filosofía 38(3):95-120

Suárez J, Stencel A (2020) A part-dependent account of biological individuality: why holobionts are individuals and ecosystems simultaneously. Biol Rev 95(5):1308-1324. https://doi.org/10.1111/ brv. 12610

Swartz SZ, Wessel GM (2015) Germ line versus soma in the transition from egg to embryo. Curr Top Dev Biol 113:149-190

Tauber AI (2016) Immunity in context: science and society in dialogue. THEORIA. https://doi.org/10.1387/theoria. 14560

Triviño V, Suárez J (2020) Holobionts: ecological communities, hybrids, or biological individuals? A metaphysical perspective on multispecies systems. Stud Hist Philos Sci C 84:101323. https ://doi.org/10.1016/j.shpsc.2020.101323

Turner S (2013) Superorganisms and superindividuality: the emergence of individuality in a social insect assemblage. In: Bouchard F, Huneman P (eds) From groups to individuals: evolution and emerging individuality. MIT Press, Cambridge, pp 219-242

Veit W (2019) Evolution of multicellularity: cheating done right. Biol Philos 34(3):34. https://doi.org/10.1007/s10539-019-9688-9

West SA, Griffin AS, Gardner A (2007) Social semantics: altruism, cooperation, mutualism, strong reciprocity and group selection. J Evol Biol 20(2):415-432

West SA, Fisher RM, Gardner A, Kiers ET (2015) Major evolutionary transitions in individuality. Proc Natl Acad Sci USA 112(33):10112. https://doi.org/10.1073/pnas.1421402112

Wilson EO (1975) Sociobiology: the new synthesis. Harvard University Press, Cambridge

Wloch-Salamon DM, Bem AE (2013) Types of cell death and methods of their detection in yeast Saccharomyces cerevisiae. J Appl Microbiol 114(2):287-298. https://doi.org/10.1111/jam.12024

Publisher's Note Springer Nature remains neutral with regard to jurisdictional claims in published maps and institutional affiliations. 